International Journal of Basic and Applied Sciences, $5(1)(2016) 90-94$
SPC
International Journal of Basic and Applied Sciences
Website: www.sciencepubco.com/index.php/IJBAS
doi: $10.14419 / j$ bas.vSil.5614
Research paper

\title{
Variations in yield and composition of leaf essential oil from Syzygium aromaticum at various phases of development
}

\author{
Gaylor Razafimamonjison ${ }^{1,2,3 *}$, Renaud Boulanger ${ }^{4}$, Michel Jahiel ${ }^{2,3,5}$, Panja Ramanoelina ${ }^{1}$, \\ Fanja Fawbush ${ }^{1}$, Marc Lebrun ${ }^{4}$, Pascal Danthu ${ }^{2,6,7}$ \\ ${ }^{1}$ École Supérieure des Sciences Agronomiques Université d'Antananarivo BP 175 Antananarivo Madagascar \\ ${ }^{2}$ Cirad DP Forêts et Biodiversité BP 853 Antananarivo Madagascar \\ ${ }^{3}$ Centre Technique Horticole de Tamatave BP 11 Tamatave Madagascar \\ ${ }^{4}$ Cirad UMR Qualisud, Persyst 34398 Montpellier Cedex 5 France \\ ${ }^{5}$ Cirad UPR Hortsys BP 11 Tamatave Madagascar \\ ${ }^{6}$ Cirad UR 105 Bsef 34398 Montpellier Cedex 5 France \\ ${ }^{7}$ Cirad Direction régionale à Madagascar BP 853 Antananarivo Madagascar \\ *Corresponding author E-mail: rdinagaylor@yahoo.fr
}

\begin{abstract}
The changes in the essential oil yield and composition from Syzygium aromaticum leaf harvested at different phases of development from young leaves to mature leaves were studied. Separation of the essential oils was conducted by steam distillation in a Clevenger apparatus for about $4 \mathrm{~h}$. Essential oils analyses were performed by GC/MS. The yield of essential oil ( $\mathrm{ml}$ per $100 \mathrm{~g}$ of DM) of the leaf following the four phases of development was in order of: young leaves $(5.1 \%)>$ expanded leaves $1(4.5 \%)>$ expanded leaves $2(4.1 \%)>$ mature leaves $(3.8 \%)$. Sixteen compounds were detected by GC/MS. Eugenol and eugenyl acetate were the dominant components. Eugenol and eugenyl acetate amount had a divergent evolution during the four expansions of leaves. When eugenol reached its highest percentages at expanded leaves $2(84.00-90.48 \%)$ and mature leaves stage $(88.32-90.22 \%)$, eugenyl acetate reached the lowest ones with, respectively, $0.96-7.16 \%$ and $0.36-1.64 \%$, but when the eugenyl acetate reached a maximum percentage at young leaves stage with $61.44-65.52 \%$, eugenol reached a minimum of $25.43-30.38 \%$. It is judicious to collect and extract $S$. aromaticum leaf in expended leaves 2 (pale green leaves) and mature leaves stage (dark green leaves) in order to obtain the optimal yield and maximum percentage of eugenol.
\end{abstract}

Keywords: Composition; Essential oil; Eugenol; Eugenyl acetate; Development phases; Syzygium aromaticum leaves; Yield.

\section{Introduction}

Cloves (Syzygium aromaticum L.) are belonged to the Myrtaceae family. The origin of this plant is Moluccas Island (Indonesia). The clove tree is an evergreen that grows up to $8-12 \mathrm{~m}$ tall, whit large leaves and sanguine flowers grouped in terminal cluster [1]. This species is an extremely aromatic plant as of the high essential oil content in its bud, stem, and leaf. Cloves essential oil shows antimicrobial, antifungal and antioxidant activity. Eugenol, the basic compound of clove oil is used as an initial substance for the fabrication of vanillin [2-14].

The comparison of the essential oils extracted from cloves bud, leaf and stem has been reported and the changes on quality and quantity of the cloves bud essential oil following various stages of growth have also been reported [12-14].

For our knowledge, little studies have reported the analysis of the $S$. aromaticum essential oil leaf at different phases of expansions. In this study, we report the variation on the leaf essential oil yield and composition following various phases of development, in order to determine the optimal harvest time for S. aromaticum.
Leaves of S. aromaticum were harvested at four phases of development, including young leaves (I), expanded leaves 1 (II), expanded leaves 2 (III) and mature leaves (IV) from five trees developed in the Analanjirofo district of Madagascar, Village of Ambodimanga II, Fokontany of Ambatombary (S 17'20' / E $\left.049^{\circ} 21^{\prime}\right)$. Complete information of various development stages, harvesting time and physical characteristics (color, length and moisture content) of leaves are showed in Table 1 and are illustrated on figure 1 .

\subsection{Essential oil isolation}

Separation of the essential oils was conducted by steam distillation in a Clevenger apparatus for about $4 \mathrm{~h}$. Distillations were performed less than $24 \mathrm{~h}$ after sampling. Essential oil yield is expressed in milliliters per $100 \mathrm{~g}$ of plant dry matter. The distillated oils were dried over anhydrous sodium sulfate $\left(\mathrm{Na}_{2} \mathrm{SO}_{4}\right)$ and stored in tightly closed dark vials at $4^{\circ} \mathrm{C}$ awaiting analysis.

\section{Experimental}

\subsection{Plant material}


Table 1: Phases of development and physical characteristics (color, length and moisture content) of S. aromaticum leaves. Means of length and moisture content with the same letter(s) have no significant difference according to Fisher test at $\mathrm{p} \leq 0.05$.

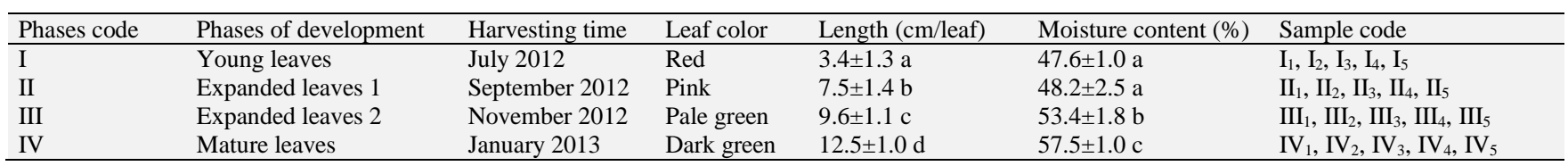

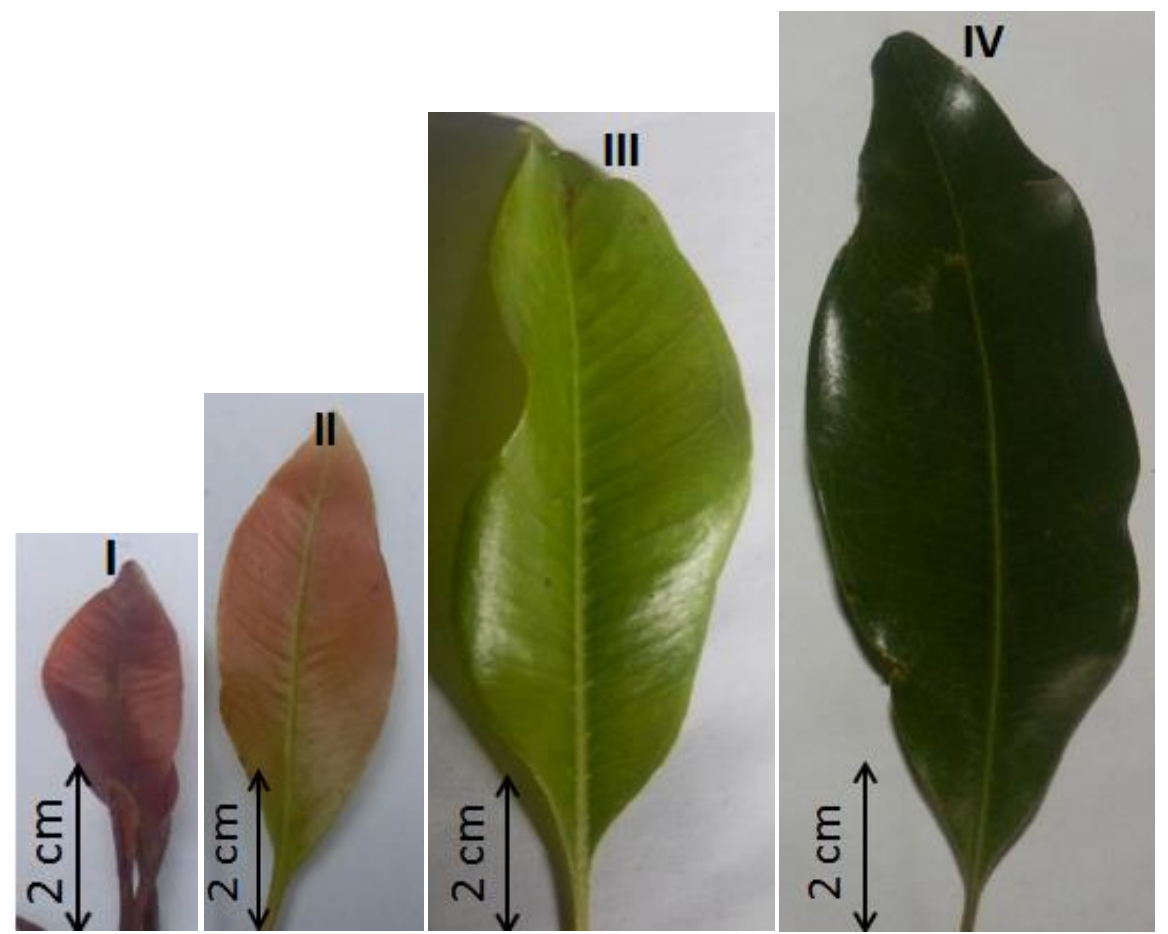

Fig. 1: Four development phases of $S$. aromaticum leaves. I, II, III, IV represents young leaves, expanded leaves 1 , expanded leaves 2 and mature leaves phases respectively.

\subsection{Oil analysis procedure}

Dried leaf essential oils analyses were made using an Agilent 6890 gas chromatograph equipped with an Agilent 5973 mass selective detector and Gerstel multipurpose sample 2 (Palo Alto, USA), equipped with fused silica capillary DB-WAX polar column ( $\mathrm{J} \& \mathrm{~W}, 30 \mathrm{~m} \times 0.25 \mathrm{~mm}$ i.d.; film thickness $0.25 \mu \mathrm{m}$ ) and a DB-1 MS apolar column (J\&W, $30 \mathrm{~m}$ x $0.25 \mathrm{~mm}$ i.d.; film thickness $0.25 \mu \mathrm{m})$ (Palo Alto, USA). Mass spectra were obtained by EI at $70 \mathrm{eV}$ within 40 to $300 \mathrm{Da}$. Carrier gas, hydrogen, was attuned at a regular run speed of $1.5 \mathrm{~mL} / \mathrm{min}$. MS source and interface temperatures were $250^{\circ} \mathrm{C}$ and $280^{\circ} \mathrm{C}$, respectively. Temperature was programmed at $3^{\circ} \mathrm{C} / \mathrm{min}$ from $40^{\circ} \mathrm{C}$ to $170^{\circ} \mathrm{C}$, then $10^{\circ} \mathrm{C} / \mathrm{min}$ up to $240^{\circ} \mathrm{C}$ and held for $10 \mathrm{~min}$. On Column Injection $(1 \mu \mathrm{L})$ was carried out at $250^{\circ} \mathrm{C}$ after dilution $1 / 2000$ in hexane.

\subsection{Identification and quantification of components}

The identification of the components was assigned by comparing their mass spectra with those of the NIST 2011 data base. Kovats retention indices were calculated with reference to n- alkanes series $\left(\mathrm{C}_{8}\right.$ to $\left.\mathrm{C}_{20}\right)$ and their comparison with those establish in Flavornet and Pherobase websites. Percentage compositions of samples were calculated according to the area of the chromatographic peaks. Concentrations are given as the average of triplicate analyses.

\subsection{Data analysis}

For comparison of the leaf length, moisture and yield essential oil mean values, Fisher's test was used. Division of the 20 essential oils was made using Principal Component Analysis (PCA). The set of data (16 volatile constituents x 20 essential oils samples) was processed mainly through XLSTAT 2014 software package.

\section{Results and discussion}

\subsection{Yield of essential oil}

The yield of essential oil leaf ( $\mathrm{ml}$ per $100 \mathrm{~g}$ of DM) following the four development phases was in order of: young leaves $(5.1 \%)>$ expanded leaves $1(4.5 \%)>$ expanded leaves $2(4.1 \%)>$ mature leaves $(3.8 \%)$ (Figure 2$)$. 


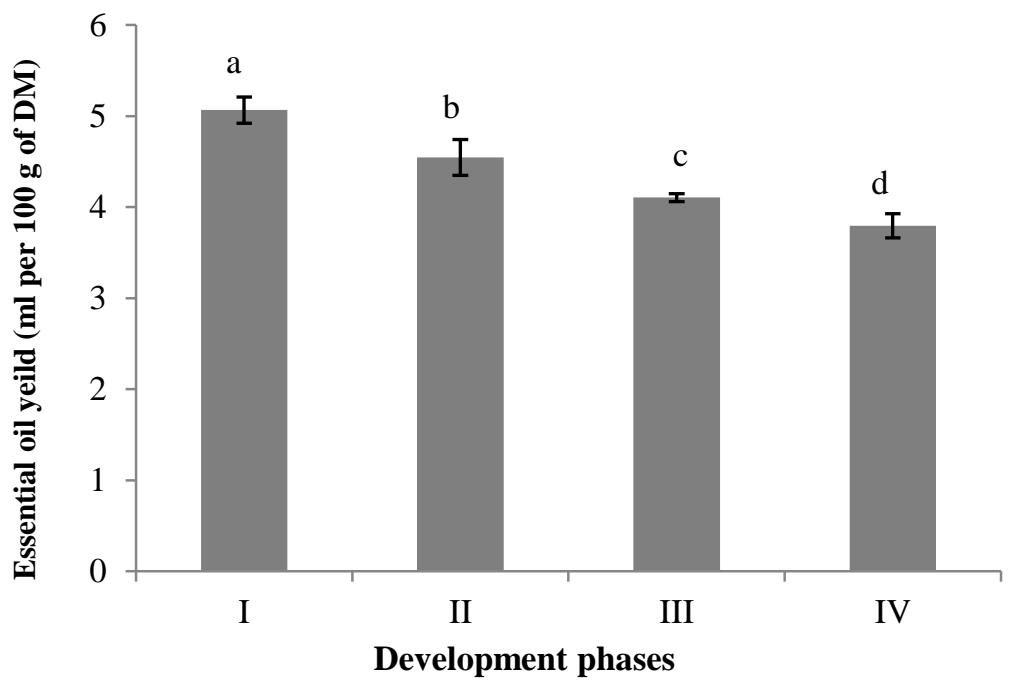

Fig. 2: Evolution in essential oil yield (ml per $100 \mathrm{~g}$ of DM) S. aromaticum leaf following the four development phases. I, II, III, IV: Same as in fig 1. Essential oil yield mean values whit different letters $(\mathrm{a}-\mathrm{d})$ were significantly different at the level of $\mathrm{P}<0.05$ according to the Fisher's test.

\subsection{Essential oil composition}

Chemical composition of $S$. aromaticum leaf essential oil was investigated by GC/MS. Sixteen compounds were identified representing an average of $99 \%$ of the oil composition. Eugenol and eugenyl acetate were the dominant components. Eugenol and eugenyl acetate percentage had a divergent evolution through the four expansions of leaves. When eugenol reached its highest percentages at expanded leaves $2(84.00-90.48 \%)$ and mature leaves stage $(88.32-90.22 \%)$, eugenyl acetate reached the lowest ones with, respectively, $0.96-7.16 \%$ and $0.36-1.64 \%$, but when the eugenyl acetate reached a maximum percentage at young leaves stage with $61.44-65.52 \%$, eugenol reached a minimum of 25.43 $30.38 \%$ (Table 2 ).

The results of the statistical analysis were as follows:

The first two Principal Components (PC) explained $55.29 \%$ of the variance including $39.44 \%$ for $\mathrm{PC} 1$ and $15.85 \%$ for PC2. Figure 3 shows the organization of the variables, on the plan PC1/PC2. PC1 was structured by eugenol, caryophyllene oxide and hy- machalene presenting a negative correlation $(-0.87,-0.84,-0.83$, respectively) and being opposed the three variables presenting positive correlations: eugenyl acetate (0.90), methyl salicylate (0.87) and $\beta$ - caryophyllene (0.73).

The PCA according to PC1/PC2 (Table 2 and figure 4) led us to organize the 20 samples analyzed into three groups: Group 1 is composed of essential oils samples extracted from young leaves $\left(\mathrm{I}_{1}-\mathrm{I}_{5}\right)$, which are characterized by lower content in eugenol $(25.43-30.38 \%)$ and higher percentage of eugenyl acetate $(61.44$ - $65.52 \%$ ). Group 2 consist of essential oils extracted from expanded leaves $1\left(\mathrm{II}_{1}-\mathrm{II}_{5}\right)$. These oils were characterized by eugenol and eugenyl acetate, detected at $58.29-61.53 \%$ and 26.67 32.65 , respectively. Group 3, formed by five essential oils isolated from expanded leaves $2\left(\mathrm{III}_{1}-\mathrm{III}_{5}\right)$ and by five essential oils isolated from mature leaves $\left(\mathrm{IV}_{1}-\mathrm{IV}_{5}\right)$ is characterized by higher content of eugenol (84.00 - 90.48\%) and lower content of eugenyl acetate $(0.36-7.16 \%)$.

Table 2: Volatile constituents (relative percentages, extreme values) of essential oil from $S$. aromaticum leaf following the four phases of development (in bolt: $\%$ on main constituents discriminates in each group).

\begin{tabular}{|c|c|c|c|c|c|c|}
\hline \multirow{2}{*}{ Constituents } & \multirow[b]{2}{*}{$\mathrm{KI}^{\mathrm{a}}$} & \multirow[b]{2}{*}{ Identification $^{b}$} & \multirow{2}{*}{$\begin{array}{c}\text { Group 1 } \\
\text { Young leaves }\end{array}$} & \multirow{2}{*}{$\begin{array}{c}\text { Group 2 } \\
\text { Expanded leaves } 1\end{array}$} & \multicolumn{2}{|c|}{ Group 3} \\
\hline & & & & & Expanded leaves 2 & Mature leaves \\
\hline$\alpha$-copaene & 1462 & $\mathrm{MS} / \mathrm{KI}$ & $0.02-0.05$ & $0.03-0.04$ & $0.02-0.04$ & $0.02-0.04$ \\
\hline$\beta$-caryophyllene & 1561 & $\mathrm{MS} / \mathrm{KI}$ & $5.64-6.97$ & $5.66-8.63$ & $5.21-5.70$ & $4.63-6.42$ \\
\hline 3,7-dimethyloctan-1-ol & 1664 & MS & $0.05-0.06$ & $0.03-0.07$ & $0.06-0.07$ & $0.02-0.08$ \\
\hline viridiflorene & 1688 & MS & $0.03-0.10$ & $0.04-0.13$ & $0.00-0.05$ & $0.04-0.06$ \\
\hline methyl salicylate & 1733 & $\mathrm{MS} / \mathrm{KI}$ & $0.03-0.06$ & $0.04-0.06$ & $0.00-0.04$ & 0.00 \\
\hline cyclohexane & 1794 & MS & $0.08-0.11$ & $0.11-0.16$ & $0.10-0.12$ & $0.10-0.13$ \\
\hline nerol acetate & 1846 & MS & $0.00-0.03$ & $0.00-0.04$ & $0.03-0.04$ & $0.02-0.04$ \\
\hline 4-allylphenyl acetate & 1927 & MS & $0.04-0.07$ & $0.00-0.10$ & $0.00-0.10$ & $0.00-0.04$ \\
\hline hymachalene & 1938 & MS & $0.25-0.50$ & $0.24-0.62$ & $0.61-0.94$ & $1.31-2.05$ \\
\hline piperazine & 1958 & MS & $0.01-0.06$ & $0.00-0.05$ & $0.01-0.05$ & $0.06-0.13$ \\
\hline caryophyllene oxide & 1993 & $\mathrm{MS} / \mathrm{KI}$ & $0.06-0.15$ & $0.03-0.08$ & $0.06-0.10$ & $0.13-0.24$ \\
\hline eugenol & 2030 & MS/KI & $25.43-30.38$ & $58.29-61.53$ & $84.00-90.48$ & $88.32-90.22$ \\
\hline eugenyl acetate & 2055 & MS & $61.44-65.52$ & $26.67-32.65$ & $0.96-7.16$ & $0.36-1.64$ \\
\hline methyl linoleate & 2062 & MS & $0.01-0.06$ & $0.00-0.05$ & $0.05-0.20$ & $0.13-0.21$ \\
\hline
\end{tabular}

${ }^{\mathrm{a}}$ Kovats Index relative to $\mathrm{n}$-alkanes $\left(\mathrm{C}_{8}-\mathrm{C}_{20}\right)$ on a DB-WAX MS Column.

${ }^{\mathrm{b}}$ KI, Kovats Index on a DB-WAX MS Column in Flavornet and Pherobase websites. MS, tentatively identified on the basis of computer matching of the mass spectra of peaks with the NIST 2011. 


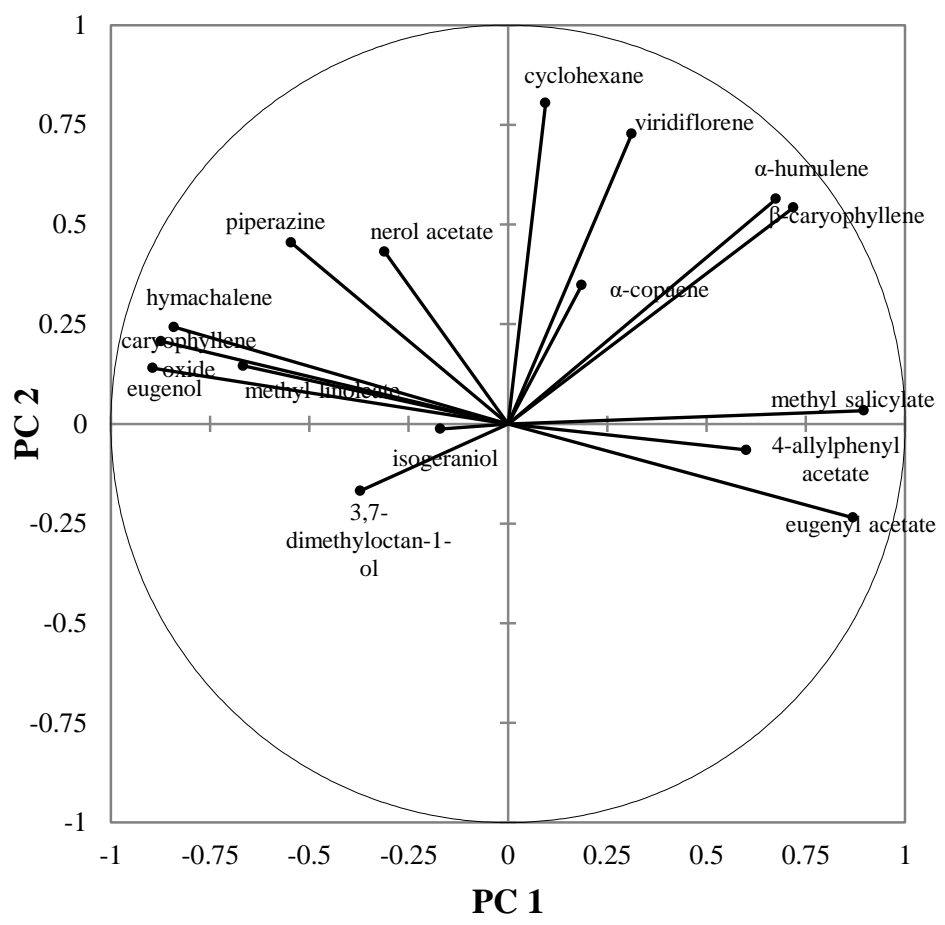

Fig. 3: Organization of the 16 variables on the plan PC1/PC2.

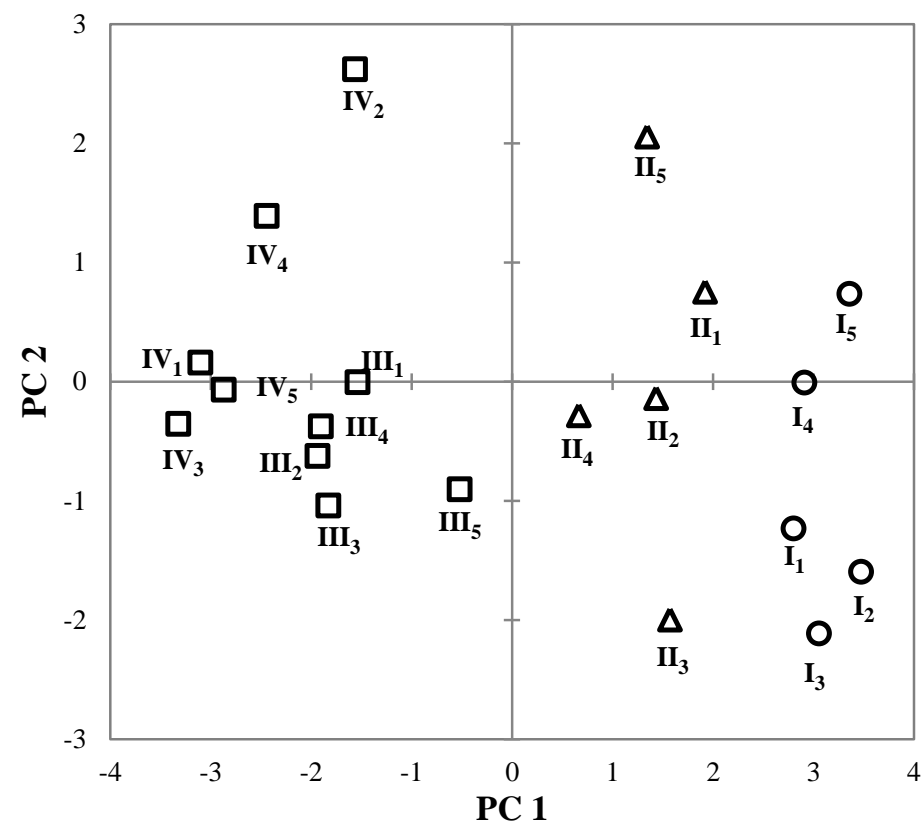

Fig. 4: Relative position of the 20 essential oils samples on the plan PC1/PC2. I, II, III, IV: Same as in fig 1 . Group 1 is represented by circle, Group 2 by triangle and Group 3 by square.

\section{Conclusion}

The results reported on the essential oil yield and chemical composition of $S$. aromaticum leaf at different phases of development revealed remarkable variations. It may be suggested that these differences could be due to the effect of harvesting time as well as the environmental conditions. We consider that for obtain the highest quantity and quality of essential oil from $S$. aromaticum leaf, it is judicious to harvest and distil S. aromaticum leaf in expended leaves 2 (pale green leaves) and mature leaves stage (dark green leaves) in order to obtain the optimal yield and maximum percentage of eugenol.

\section{Acknowledgements}

This study was approved away as part of the DP/FB work, a joint project between CIRAD, École Supérieure des Sciences Agronomiques University of Antananarivo and the CTHT. Financial assistance has been appreciatively acknowledged from the French Ministry of Foreign Affairs (projects "Girofle" and "Innovépice", supported by FSP PARRUR), the AFS4FOOD project (EuropAid, European Union/African Union) and CIRAD.

\section{References}

[1] P. Danthu, E. Penot, K. M. Ranoarison, J. C. Rakotondravelo, I. Michel-Dounias, M. Tiollier, T. Michels, F. Normand, G. Razafimamonjison, F. Fawbush, M. Jahiel, "The clove tree of 
Madagascar: a success story with an unpredictable future", Bois et forêts des tropiques, 320, 2, (2014), 83 - 96.

[2] A. Srivastava, S. Srivastava, K. Syamsundar, "Bud and leaf essential oil composition of Syzygium aromaticum from India and Madagascar", Flavour and Fragrance Journal, 20, (2005), 51 - 53.

[3] F. Chami, N. Chami, S. Bennis, T. Bouchikhi, A. Remmal, "Oregano and clove essential oils induce surface alteration of Saccharomyces cerevisiae", Phytotherapy Research, 19, (2005), $405-408$.

[4] M. Miyazawa, M. Hisama, "Suppression of chemical mutagen induced SOS response by alkylphenols from clove (Syzygium aromaticum) in Salmonella typhymurium.", Journal of Agricultural and Food Chemistry, 49 , (2001), 4019 - 4025.

[5] M. Ogata, M. Hoshi, S. Urano, T. Endo, "Antioxidant activity of eugenol and related monomeric and dimeric compounds", Chemical \& Pharmaceutical Bulletin, 48, (2000) 1467 - 1469.

[6] I. Park, S. Shin, "Fumigant activity of plant essential oils and components from garlic (Allium sativum) and clove bud (Eugenia caryophyllata) oils against the Japanese termite (Reticulitermes speratus)", Journal of Agricultural and Food Chemistry, 53, (2005), $4388-4392$.

[7] T. Tworkoski, "Herbicide effects of essential oils", Weed Science $50,4,(2002), 425-431$

[8] W. Wannes, B. Mhamdi, B. Marzouk, "Variations in essential oil and fatty acid composition during Myrtus communis var. italica fruit maturation", Food Chemistry, 112, (2009), 621 - 626.

[9] H. Kim, E. Lee, S. Hong, "Effect of Syzygium aromaticum extract on immediate hypersensitivity in rats", Journal of Ethnopharmacology, 60, (1998), 125 - 131.

[10] V. Raina, S. Srivastava, K. Aggarwal, K. Syamasundar, S. Kumar, "Essential oil composition of Syzygium aromaticum leaf from Little Andaman, India", Flavour Fragrance Journal, 16, (2001), 334 - 336.

[11] G. Zheng, P. Kenney, L. Lam, "Sesquiterpenes from clove (Eugenia caryophyllata)", Journal of Natural Products, 55, (1992), 999 - 1003.

[12] G. Razafimamonjison, M. Jahiel, P. Ramanoelina, F. Fawbush, P. Danthu, "Effects of phenological stages on yield and composition of essential oil of Syzygium aromaticum buds from Madagascar", International Journal of Basic and Applied Sciences, 2, 4, (2013), $312-318$.

[13] E. Gaydou, R. Randriamiharisoa, "Multidimentional analysis of Gas chromatographic data, application to the differenciation of clove bud and clove stem essential oil from Madagascar", Parfumer \& Flavorist, 12, (1987), 45 - 51.

[14] G. Razafimamonjison, M. Jahiel, P. Ramanoelina, F. Fawbush, P. Danthu, "Bud, leaf and stem essential oil composition of Syzygium aromaticum from Madagascar, Indonesia and Zanzibar", International Journal of Basic and Applied Sciences, 3, 3, (2014), $224-233$. 